\title{
Collaborative Learning in Building Sciences Enabled by Augmented Reality
}

\author{
Shahin Vassigh ${ }^{1, *}$, Winifred E Newman ${ }^{1}$, Amir Behzadan², Yimin Zhu ${ }^{3}$, Shu-Ching Chen ${ }^{4}$, Scott Graham ${ }^{4}$ \\ ${ }^{1}$ Department of Architecture, Florida International University, Miami, Florida, US \\ ${ }^{2}$ Department of Civil, Environmental University of Central Florida, Orlando, Florida, US \\ ${ }^{3}$ Department of Construction Management, Florida International University, Miami, Florida, US \\ ${ }^{4}$ School of Computing and Information Sciences, Florida International University, Miami, Florida, US \\ *Corresponding author: svassigh@fiu.edu
}

Received January 12, 2014; Revised March 11, 2014; Accepted April 28, 2014

\begin{abstract}
This paper presents a comprehensive literature review, a novel pedagogical approach, and plans for developing and testing a collaborative learning environment built upon the capacity of new simulation technologies and augmented reality (AR) for improving sustainable and resilient building design. The project aims at integrating collaborative learning strategies with new simulation technologies and AR to provide a learning environment for interdisciplinary education of architecture, engineering, and construction (AEC).
\end{abstract}

Keywords: Augmented Reality, collaborative learning, sustainability of built environment

Cite This Article: Shahin Vassigh, Winifred E Newman, Amir Behzadan, Yimin Zhu, Shu-Ching Chen, and Scott Graham, "Collaborative Learning in Building Sciences Enabled by Augmented Reality.” American Journal of Civil Engineering and Architecture, vol. 2, no. 2 (2014): 83-88. doi: 10.12691/ajcea-2-2-5.

\section{Introduction}

The construction, operation, maintenance, and management of the built environment critically impact the economy and the habitat. The U.S. building sector is one of the planet's largest contributors to climate change. The construction and operation of buildings in the U.S. is among the most energy, pollution, and resource intensive of all human activities, consuming $49 \%$ of the nation's total energy and $77 \%$ of its electricity each year. Materials utilized in buildings have high-embodied energy, contain high levels of toxins and pollutants, and give off high levels of emissions [1].

Extensive research by the National Institute of Building Sciences (NIBS) and others has shown that the most resource efficient, best performing, and environmentally sustainable buildings are designed using Integrated Design. Integrated Design is the process by which engineers, architects, and construction professionals work together during the planning, design, and conception of a project to create synergy among various building systems and improve overall building performance. Research shows that when architects, structural, mechanical and electrical engineers, construction managers, and others involved in building science collaborate early and effectively at the start of a building design project, their collaboration produces better designed, more efficient, and lower cost buildings [2].

Promoting the practice of Integrated Design has been recognized by the American Institute of Architects (AIA) as one of the central challenges facing the profession, and one of the most important ways to improve building performance, cost, and environmental impact. The AIA 2030 Commitment challenged the profession to achieve the goal of designing carbon-neutral or no greenhouse gas emitting buildings in the U.S. and identified the practice of Integrated Design as the primary vehicle to attain this goal [3].

However, despite recognition of Integrated Design as a significant step towards designing sustainable buildings, it is far from becoming a standard mode of architectural practice. The fundamental problem is that both the educational system and professional practice of the disciplines responsible for building design and construction - Architecture, Engineering and Construction (AEC), are split into increasingly specialized and fragmented components — professional and knowledge "silos," within which architects, engineers, and construction managers fail to communicate and collaborate effectively.

Though large-scale reform of AEC education is a complex, ongoing, national debate; researching learning environments that support developing collaborative skills for interdisciplinary interaction is critical in bridging knowledge silos. To this end, current advances in technology and cyberspace capacity coupled with emerging research in engineering education are creating new promising opportunities for educational reform in the area of collaborative learning.

Extensive research details how technology- mediated learning environments (interacting with computer-based tools) can enhance learning. Augmented Reality (AR) the ability to overlay computer information onto the real world, in real time, and shared by multiple users — will 
be critical in developing the next generation of computerbased learning environments. Unlike computer interfaces that draw users away from the real world, AR technology enables interaction with the real world in ways never before possible [4] and [5]. AR is already transforming a diverse array of professions including medicine, the military, aircraft navigation, entertainment, publishing, and education.

Although there are few fully integrated, complete, effective, and readily usable AR educational environments, the authors of this paper hypothesize that AR technology can be an effective vehicle for interdisciplinary and collaborative learning. This paper presents the research, pedagogical approach, and plans for developing and testing a collaborative learning environment built upon the capacity of new simulation technologies and AR for improving sustainable and resilient building design.

\section{Augmented Reality in Interdisciplinary Education}

AR Interfaces blend the physical and virtual worlds so real objects can interact with 3D digital content and improve users' shared understanding [6] and [7]. Research indicates that new developments in AR and improved user interface technology presents numerous opportunities for support of teaching and learning environments [8]. Yuen summarizes recent findings on potential benefits of AR in education and asserts that AR can: 1) engage, stimulate, and motivate students to explore lessons and concepts from different angles, 2) enhance learning where students could not feasibly gain real-world first-hand experience, 3) enhance collaboration between students and teachers, 4) foster student creativity and imagination, 5) aid students to control their learning at their own pace and on their own path, and 6) create an authentic learning environment suitable to various learning styles [8].

Similar findings have been cited on simulation technologies. During the first decade of the $21^{\text {st }}$ century there was significant progress in the educational use of simulation and data visualization techniques. Many studies show that using visualization techniques in the learning environments motivates and engages students' indepth investigation of concepts [9] (Shirazi and Behzadan 2013). A recent book published by the National Research Council Committee (NRCC) on Science Learning states that simulations and data visualization are enabling learners to see and interact with representations of natural phenomena that would otherwise be impossible to observe: a process that helps them formulate scientifically correct explanations for these phenomenon [10].

Concurrent research shows favorable results for learning in technology-rich environments where the capacity of cyber space to facilitate data storage and access has vastly increased. Networks of interdependent information technology infrastructure further facilitate the creation and integration of educational environments. In the realm of data processing, one critical challenge is the timely management and efficient processing of data to support end-user tasks. In the case of AR technology in particular, the inability to generate virtual information and deliver this information in absolute real time limits the creation of realistic augmented views responsive to a user's context. The process of creating, obtaining, refining, rendering, archiving, and updating the virtual content and large datasets (which is often referred to as model engineering) may turn out to be costly and computing intensive [11].

However, it is now possible to leverage advances in network information technology infrastructure, and computer processing systems to provide functionality allowing the generation of virtual contents ahead of time, storing them in an easy-to-access place (i.e. cyber space), and delivering them to the end users in real time based on the needs of the tasks at hand.

\subsection{Approach and Perspectives on Learning}

In developing any educational application it is critical to understand the theoretical perspectives and advances in one's understanding of learning processes, cognition, and development. Such understanding is critical in identifying strategies and methods that are appropriate to the needs and proclivities of learners. Based on authors' research, the following three approaches were identified that provide an appropriate context for interdisciplinary learning for AEC students.

Project Based Learning: One of the most researched learning models in the last decade is project- based learning. In a project-based approach, learning is organized around the investigation, explanation, and resolution of meaningful problems [12]. In this approach, students learn through experience of working through problems, and learning centers on a complex situation or problem that does not have a single correct answer. Psychological research and theory suggests that by having students learn through the experience of solving problems, they can learn both content and thinking strategies [12].

Collaborative Learning: Studies also indicate that project-based learning is enhanced in a collaborative environment. Working in groups allows students to reflect on their learning and the effectiveness of the strategies employed. Smith and MacGregor state that learning is an active, constructive process that is inherently social. In collaborative learning situations, students create something new with the information and ideas. They further argue that collaborative learning brings about intellectual synergy of multiple minds coming to bear on a problem by engaging them to gather, share and develop collective insight -"this mutual exploration, meaningmaking, and feedback often leads to better understanding on the part of students, and to the creation of new understandings for all of us” [13]. Collaborative learning is rooted in a socio-cultural model of educational psychology described by Lev Vygotsky (1962, 1978). The socio-cultural model focuses on how social interaction affects cognitive development [14]. But rather than focusing on an individuals' actions, the emphasis is on the role of interactions with others. The socio-cultural, or dialogic 'situated learning model', focuses on the causal relationships between social interactions and an individuals' cognitive change. From a Vygotskian perspective, inter-psychological processes are themselves internalized by the individual involved. This is based on Vygotsky's "genetic law of cultural development" which states that development appears on two planes: first on the inter-psychological and then in the intra-psychological [15]. 
Interaction with a Device: A second aspect of Vygotsky's theory is the meditating role of artifacts in activity. Underscoring the idea of a genetic approach to human learning, Vygotsky argued that humans are unique in that they are born into environments shaped by the activities of previous generations. The human capacity to make and use artifacts is therefore a key component in our ability to learn as we enrich and extend knowledge through an individual's appropriation and mastery of the cultural inheritance [16]. Our project builds on the idea of devices enabled by application programming interfaces (APIs) as an important tool whose portability, explicability, and storage capacity is a fundamental asset in facilitating group interaction.

To understand how this might work, imagine one group of students working around a virtual model of a building seen only on a computer screen. Their body postures focus toward the screen, eyes following movement on the screen; their conversational space limited by furniture, cables, and the other devices necessary to support a fixed computer arrangement. A second group of students works around a model in a physical space, but using handheld devices (smart phones, tablets) with AR capability that allows them to "see" a data-rich virtual environment in relation to the real model. Their posture faces toward the model or toward each other.

They can move around each other or the model holding the portable interface and additionally toward a desktop computer for calculations, notes and storage of information. The dynamic of the group is not limited by the location of the computer - the handheld device is part of the physical space of the group interaction. It is not only the tools, but the social interaction in which they are embedded that is significant [16]. The handheld, portable device enables a different social space with arguably a wider variety of potential interactions, from gesture to speech, body posture, and visual connectivity between group members. Evidently, engendering dialogue though interaction is fundamental to the socio-cultural approach advocated by Vygotsky.

Testing Collaborative Learning through Interaction with a Device: We conducted a brief experiment at Florida International University (FIU) to examine how collaboration could work among architects and engineers. The goal of the experiment was to study the differences between individual and collaborative learning strategies among AEC students. The experiment asked if student collaboration would result in the design of more efficient and sustainable buildings. The experiment was structured as follows: two groups of students were given the task to design and assemble a small-scale building from a given kit of parts. The main goal was to design an energyefficient building with minimal impact on the environment. During the process, students were given access to disciplinary content, lessons and information about the climate and the locale of the building, as well as existing strategies that could be incorporated into the design. In addition, textual and graphic handouts accompanied each element with respect to its particular metrics and attributes.

The first group (Group 1) acted independently assuming their respective roles as Architect, Mechanical Engineer, and Construction Manager. Students consulted each other as needed. The second group of students (Group 2) collaborated from the beginning of the project and stayed together to complete the building assembly. The experiment was closely monitored and student interactions were recorded. The assembled building for each group was collected and modeled in a digital format with the inclusion of an individual elements' metrics. Both buildings were analyzed with Energy Plus software for cost, carbon footprint, and energy consumption.

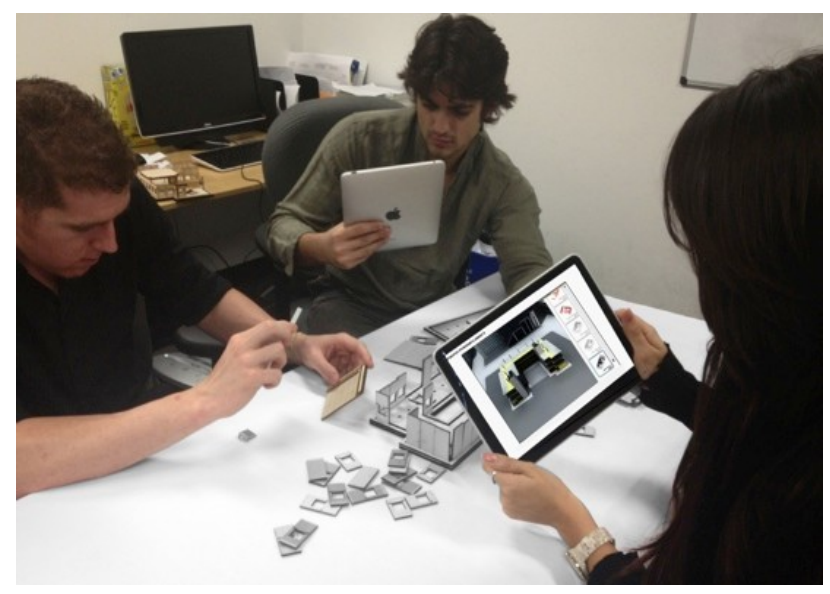

Figure 1. Students inteacting with ecoBlox leraning environement

The resulting data showed that the second groups' building assembled in a collaborative learning environment performed better in all categories of energy consumption, embodied energy, embodied water, and lifecycle cost, but the initial cost of construction was higher. Later analysis revealed that the initial cost increase was offset after five years due to the resulting energy savings. To understand the process we reviewed the video recordings of student interactions and observed that students were initially hesitant about voicing their opinion in decisions not directly related to their disciplines. However, as they spent time together negotiating and discussing the decision-making process, their natural disciplinary constraints and conflict of interests resulted in a richer and more nuanced discussion of fundamental concepts that we believe contributed to the success of the group project.

In the exit interview, students working in the more effective Group 2 identified two challenging aspects of the experimental setup: first, the difficulty of negotiating with their partners across disciplinary boundaries that was expected, and second, the amount of time it took to stop the discussions and look for information that they could not access effectively through the provided print package. It was this second aspect of their observations that was not anticipated. This aspect served as the basis for the presented work.

\subsection{Collaborative Learning Environment Project}

The authors aim at planning an alternative approach to the traditional use of physical architectural models as a representational tool. Architectural models are almost always used to communicate the massing and general organization of a building. Although there is significant time and effort spent by students to refine these models, the learning process is trumped by composing the building geometry without any attention to the performance of the overall form. 
Utilizing AR technology for embedding critical lessons and information with respect to materiality, performance metrics, systems capabilities, and the carbon footprint of building elements, onto the varied components of the architectural model can transform models to "smart" objects. Constructing or assembling "smart" components in an interdisciplinary collaborative process can support learning in a meaningful way.

To facilitate this type of learning environment, we are in the planning stages of developing ecoBlox, a 'kit of parts' composed of small-scale physical models of building components embedded with AR markers, and a user friendly software interface. The kit includes laser-cut, small-scale wood elements with a number of variations and extensive choices representing each building element such as floor plans, walls, roofs, structure, and mechanical systems. A laser cutter will be used to score each physical component with an AR marker.

The physical model components will be embedded with an AR codes activated by a mobile device such as an iPad, iPhone, or an Android device.

When the embedded markers in the physical components are held in front of the built-in camera of an AR-enabled mobile device, they activate digital information that is superimposed over the views of the physical models. As students work together to perform an activity using the physical components, they learn about the attributes of each component through audio narrated text, virtual case studies, simulations, exploded axonometric illustrations, and interactive drawings and tabulated metrics.

The ecoBlox interface will include a digital catalogue of each building element with physical properties and attributes: specific weight, thickness/size, thermal resistance (R-Value), rate of heat loss (U-Factor), embodied energy, embodied water, and initial and life cycle cost. The AR markers will activate this information. The ecoBlox interface will also provide access to software that delivers the entire educational content. In addition, it will integrate an easy to use interface that uses the worldwide web (i.e. internet) for accessing geospatial data such as site and climatic data, sun angles, and wind patterns and speed. Since students and instructors have free access to Wi-Fi Internet on campus and/or that 3G-4G mobile Internet is becoming more widespread, this approach significantly reduces the processing time while giving application developers the flexibility to update or modify parts the application from a remote server without having to physically access each and every mobile device used by the students.

ecoBlox Learning Experience- Consider the following scenario:

An interdisciplinary team of students is given the task to assemble a building from the ecoBlox physical kit- ofparts. The team's mission is delivered as a short movie through a mobile device equipped with the "ecoBlox" Interface. The movie shows them a scenario for the design and construction of a building, which for the purposes of our discussion is located in Phoenix, Arizona's Camelback area, a hot and arid climate. The team is tasked to negotiate a number of strategies, evaluate alternatives, and select systems and processes that lead to the design of an energy efficient, low cost building with minimal impact on the environment.
Students begin to investigate potential options by engaging with the ecoBlox kit with a wide range of components such as floor templates with various geometries, structural elements, climate control systems, and façade systems. A team member begins by randomly picking a façade system, and holding the mobile device over the selected element. Once launched, the AR application shows the menu of the ecoBlox interface with a series of icons. Students select the physical attributes indicated by these icons. They can then "see" properties including thermal resistance, embodied energy and water, percentage of recycled materials, weight, and cost per square foot for the part in hand through the mobile AR device. Other team members begin to interact with the ecoBlox application by pressing the visualization icon. This leads to additional information of highly detailed and realistic three-dimensional (3D) models of the façade system introducing all the component of the system hyperlinked to textual, audio narration, and animations that deliver key concepts and lessons necessary to understand the building system.

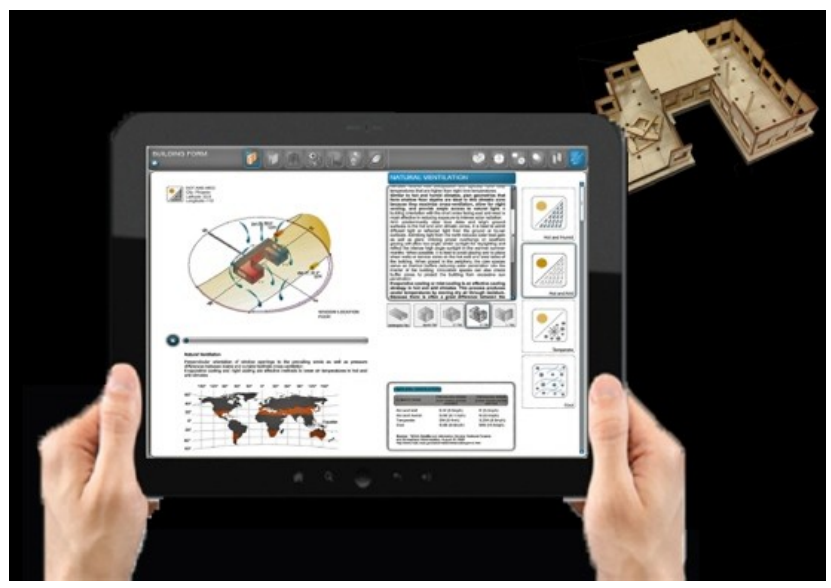

Figure 2. Screen showing ecoBlox software interface

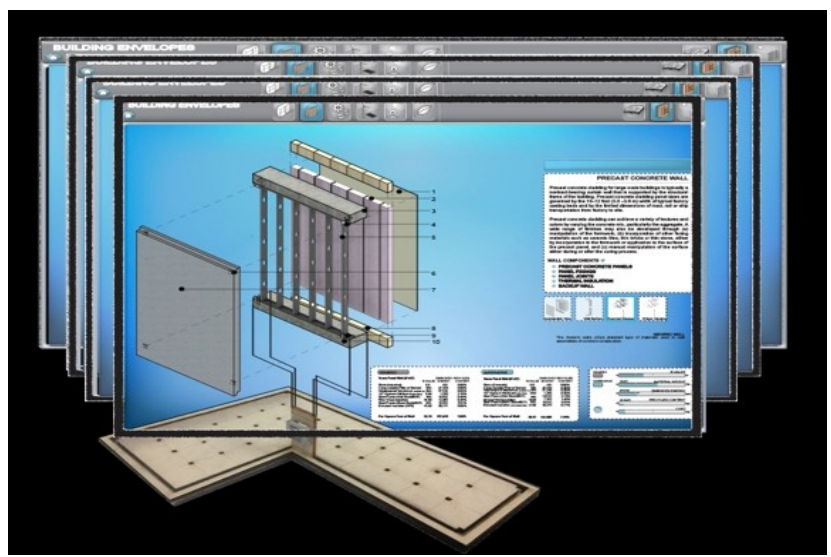

Figure 3. Screen showing detail investigation of a façade system

Moving the mobile device around a number of different façade systems and looking at various information triggers a discussion among the team members. Their resulting design may end up having a higher cost, but a lower carbon footprint. A structural engineering student discusses his/her concern about the possible compatibility issues that will arise when a structural system is selected in the later stages. The mechanical engineer brings up questions on the sensitivity of solar orientation and its 
impact on energy consumption. Each choice involves a set of trade-offs that must be negotiated by team members.

As the team members continue discussing their conflicts biased by their disciplinary constraints and perspectives, they refer back to the ecoBlox application for more in-depth analysis and data. At this point, the ecoBlox system prompts students to look at a case-study icon that has not yet been utilized or discovered. The team pulls up information concerning how this particular façade system has been utilized in an existing real building and looks at performance metrics in service conditions.

As the team moves forward to select a floor template, they are prompted to choose a climatic condition and the exact site location of the project on the map. By clicking the hot and arid climate box on the screen to match the Phoenix locale, a simulation will show a floor template built into a 3D building volume placed on their particular site. Interacting with the screen the team rotates the building volume and looks at the impact of building orientation on the energy consumption of the building through metrics exhibited on the screen. The team investigates a number of floor templates and their volumetric behavior, and surface-to-volume aspect ratios. They begin assembling the façade system together with the floor template by physically mounting the façade system on the floor template through fitted connections.

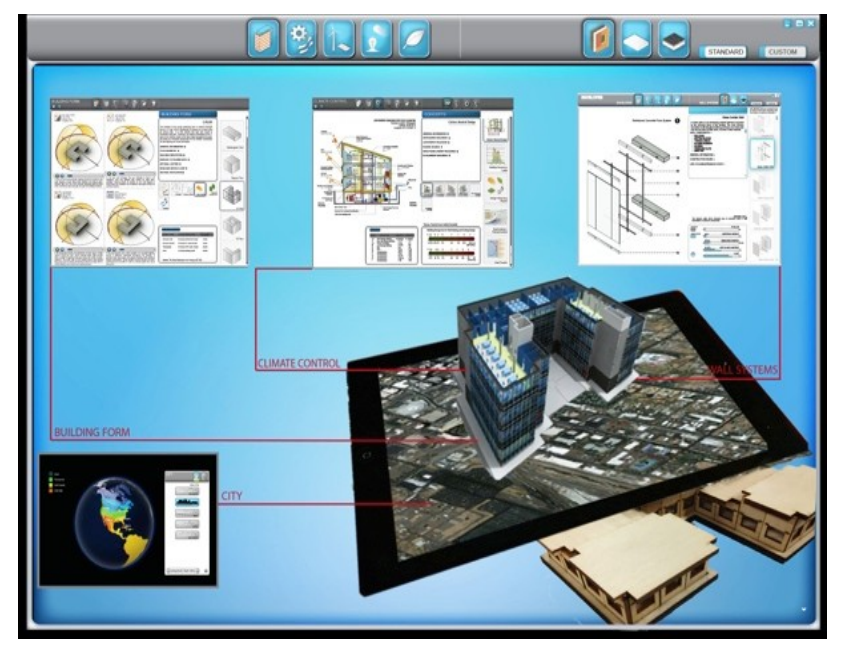

Figure 4. Screen showing an assembled building with ecoBlox

The team moves toward completion by selecting the structural system, mechanical systems, and all other building components, evaluating the advantages and disadvantages of each component, and discussing various strategies.

As team members have different expertise, the ecoBlox interface prompts the respective student expert (through relevant icons) to lead the discussion in their discipline. Each domain expert has privileged access to detailed information, sample calculations, and additional in-depth information. This assumes that the student expert has prior knowledge, can grasp concepts quicker and contribute more to the discussion. While the team negotiates alternatives, they constantly adjust the physical model by changing a number of elements to eliminate inconstancies with the overall design strategy. Eventually, ideas with respect to the building's overall shape, volume, orientation, structure, active/passive cooling systems, façade openings, shading devices, and construction methods take form and group strategies become concrete. Upon completion of the physical model, the building is submitted for analysis and the team receives the performance metrics of the assembly.

\section{Discussion and Conclusions}

This project examines how the integration of immersive visualization technology with physical building models, simulation applications, and geospatial data can promote conceptual thinking and improve learning through collaboration in AEC students. The proposed test bed will build upon previous research in collaborative learning environments at university level education.

Our research plan provides a roadmap to assess the effectiveness of the proposed environment and address the broader research questions. However, the specific objectives of the research can only be met through additional testing simulations with human participants. Our next steps are to 1 ) create a robust AR experimental setting with students representing the AEC disciplines, 2) monitor, evaluate, and compare their performance to students in an unenhanced collaborative setting, and 3) develop courses integral to the architecture and engineering curricula. We would stress that the importance of successfully using new technologies in the classroom must be accompanied by professional training for instructors. Our methods will be published online and made available to a wide audience in the interest of forwarding the research and practice of using AR in education. If current trends continue apace it is not a question if AR is going to be adopted into the classroom, but when and how.

\section{Acknowledgement}

This material is based upon work supported by Department of Education the Fund for Postseconda Education \& the National Science Foundation under Grant Nos. HRD-0833093, IIP-0829576, and IIP-1338922.

\section{References}

[1] UNEP, Pekka Huovila. "Building and Climate Change." Status Challenges and opportunities, United Nations, Environment Program, Sustainable Consumption and Reduction Branch, illustrated edition, 2007.

[2] National Institute of Building Sciences Annual Report, 2012 [Online]. Available: nibs_2012_annualreport_sm.pdf. [Accessed March. 10, 2014].

[3] American Institute of Architects (AIA) “Architecture 2030 will Change the Way You Look at Buildings”. [Online]. Available: http://architecture2030.org/the_problem/buildings_problem_why. [Accessed March. 10, 2014].

[4] Billinghurst, Mark, “Augmented Reality in Education”, December 2002.[Online]. Available:

http://www.solomonalexis.com/downloads/ar_edu.pdf.[Accessed March. 10, 2014].

[5] Behzadan A.H., Dong S., Kamat V.R. (2012), “Mobile and Pervasive Construction Visualization Using Outdoor Augmented Reality, In Mobile and Pervasive Computing in Construction, Eds. Chimay J. Anumba and Xiangyu Wang, John Wiley \& Sons, United Kingdom, 2012, 54-85.

[6] Azuma R., A Survey of Augmented Reality, Tele-operators and Virtual Environments, Presence: Teleoperators and Virtual Environments 6,4, August 1997, 355-385. 
[7] Billinghurst, M. and Kato, H. Collaborative Augmented Reality. IEEE Communications of the ACM, 45 (7), 2002, 64-70.

[8] Yuen, S., G. Yaoyuneyong, and E \& Johnson. "Augmented reality." An overview and five directions for AR in education. Journal of Educational Technology Development and Exchange, 2011: 4(1), 119-140.

[9] Shirazi A., Behzadan A.H. "Assessing the Pedagogical Value of Augmented Reality-Based Learning in Construction Engineering”, In Proceedings of the 13th International Conference on Construction Applications of Virtual Reality (CONVR), London, UK. 2013.

[10] National Research Council (NRC), Informing Decisions in a Changing Climate. The National Academies Press, Washington DC., 2009. [Online]: Available:

http://www.nap.edu/catalog.php?record_id=12626.[Accessed March. 10, 2014].

[11] Brooks, F.P., Jr. (1999) "What’s real about virtual reality?" IEEE National Research Council of the National Academies, "Learning
Science Through Computer Games an Simulations”, The National Academies Press, Washington DC, 2011.

[12] Hmelo-Silver, Cindy E., Problem-Based Learning: What and How Do Students Learn?, 2004, 235-261.

[13] Smith, B., Macgregor, J. What is Collaborative Learning? Washington Center for Improving the Quality of Undergraduate Education, 2013 [Online]: Available:

https://umdrive.memphis.edu/ggholson/public/collab.pdf, P.2. [Accessed March 10, 2014].

[14] Doise, W. \& Mugny, W., "The Social Development of the Intellect”. Oxford: Pergamon Press. [1984].

[15] Dillenbourg, P., Baker, M., Blaye, A. \& O’Malley, C. "The evolution of research on collaborative learning." [1996].

[16] Wells, G., Dialogic Inquiry in Education: Building on the Legacy of Vygotsky, 1999. [Online]. Available: https://www.csun.edu/ SB4310/601\%20files/dialogicinquiry.pdf. 